\title{
The Effect of Parental Smoking on the Severity of Asthma in Children: A Cross-Sectional Study
}

\author{
Carla Irani, ${ }^{1}$ Olga Nahas ${ }^{1} \& \mathrm{Jad}_{\text {Saliba }}{ }^{1}$ \\ ${ }^{1}$ Internal Medicine Department, Hôtel-Dieu de France Hospital, Alfred-Naccache Avenue, Beirut, Lebanon \\ Correspondence: Carla Irani, Internal Medicine Department, Hôtel-Dieu de France Hospital, St Joseph University, \\ Alfred-Naccache Avenue, Beirut, Lebanon. Tel: 961-349-5496. E-mail: iranica@yahoo.com
}

Received: October 19, 2017 Accepted: November 27, 2017 Online Published: December 6, 2017

doi:10.5539/gjhs.v10n1p140 URL: https://doi.org/10.5539/gjhs.v10n1p140

\begin{abstract}
Background: Several environmental factors trigger attacks of asthma by immunological and non-immunological mechanisms. Among these factors are cited the passive or second hand smoking (SHS) which has a deleterious effect on the prognosis of childhood asthma and induces a resistance to treatment by corticosteroids. The aim of the present study was to identify parents of children with asthma who are smokers and to explore the possible negative impact of SHS exposure on the disease of asthmatic children.

Materials and Methods: A cross sectional study was conducted from February 2012 to February 2013.The study population consisted of children with asthma. The information concerning the patients was collected from their medical records filled out by the physician in a clinical setting in direct communication with the patients, or their parents when it is a little child. A group of 100 children age between 2 and 15 years, with asthma were recruited for the study. The study children were divided into two groups: cases with 28 children from smoking families, and controls with 73 children from non-smoking families. Analysis of the number of respiratory infections, asthma exacerbations per year, and the average number of hospitalization was done in both groups.

Results: Pearson chi2 test was adopted. We showed that smoking among the father was positively correlated with a higher number of hospitalizations for asthma, higher incidence of lower respiratory tract infections and asthma exacerbations. Similarly, the maternal smoking was positively correlated with a higher number of hospitalizations for asthma, lower respiratory tract infections and asthma exacerbations.

Conclusion: Passive smoking causes respiratory illness, asthma, poor growth, neurological disorders in children. To avoid the risk of respiratory and allergic diseases by environmental tobacco smoke, absolute smoking cessation by parents is strongly recommended.
\end{abstract}

Keywords: parental smoking, asthma in children, cross-sectional study

\section{Introduction}

Several environmental factors trigger asthma attacks by immunological and non-immunological mechanisms. Among these factors is exposure to passive smoking (Quinto et al., 2013), which has a deleterious effect on the prognosis of childhood asthma and induces resistance to treatment by corticosteroids (Stapleton et al., 2011; Radic et al., 2011). Recent studies still show parental smoking as the number one environmental exposure that causes asthma in the pediatric population (Nhlbi, 2007; Burke et al. 2012). Evidence shows that children who are exposed to passive parental smoking have a higher prevalence of respiratory symptoms such as cough, sputum, and wheezing (California Environmental Protection Agency \& Agency, 1997; (US), 2006; Cheraghi \& Salvi, 2009). A meta-analysis showed a relative risk ranging from 1.23 to 1.5 for asthma, wheezing, coughing with sputum production, or dyspnea in exposed subjects compared to the non-exposed (Centers for Disease Control and Prevention (US) \& U.S. Department of Health and Human Services, 2006). Exposure to passive smoking is associated with a higher prevalence of more severe asthma with increased hospitalization and prolonged length of stay (Ojukwu \& Robinson, 2017; Wang et al., 2015), more exacerbations, bronchial hyper-responsiveness (Gilmour et al. 2006; Comhair et al. 2011), and a poor respiratory function (Oconnor et al., 1987). This association could be explained by a higher risk of lower respiratory tract infections during childhood or may be secondary to other pathophysiological mechanisms such as chronic lung inflammation (Samet et al., 1983). Our aim is to explore the impact of parental smoking on asthmatic children. 


\section{Materials and Methods}

We conducted a year-long cross-sectional study at the outpatient allergy clinic of Hôtel-Dieu de France Hospital, Beirut, from February 2012 until February 2013. The study population consisted of 100 asthmatic children, between two and 15 years of age. We chose them regardless of previous asthma treatment and other confounding factors (e.g. indoor pollution due to cooking fuel, household mold, pets, etc.). Smoking in enrolled subjects was an exclusion criterion. Medical records were reviewed confidentially after obtaining the approval of the ethical committee of Hôtel-Dieu de France Hospital, Saint Joseph University. The diagnosis of asthma was already set by the clinician based on clinical history and spirometry in subjects above seven years old. The variables were a family history of smoking, the total serum immunoglobulin IgE level, skin prick test results, the existence of allergies other than asthma, and the presence of pets at home. The outcomes recorded were the number of asthma exacerbations and lower tract respiratory infections per year, the severity of asthma accordingly to the asthma symptom score, and the average number of hospitalizations per year. Children were divided into two groups: 28 patients living with family members that smoked, and a control group of 73 children living with non-smoking family members. We assessed the impact of second hand tobacco smoke on children's asthma by comparing the disease's burden in these two groups.

\section{Results}

One hundred and one asthmatic children participated in the study, among them, 28 were exposed to passive smoking and 73 had no exposure to tobacco smoke. Exposure to pets, in addition to total IgE, prick test results, and specific IgE are presented in Table 1. Both groups displayed similar results regarding pets, while almost 50 percent of the exposed children had a total IgE level superior to $120 \mathrm{KU} / 1$ compared to 75 percent of those unexposed to tobacco smoke.

Table 1. Pet exposure, prick test, specific IgE, and total IgE results in the two study groups

\begin{tabular}{|c|c|c|c|}
\hline & & Patients exposed to smoking (28) & Patients not exposed to smoking (73) \\
\hline \multirow[t]{2}{*}{ Pets at home } & Dogs & 2 & 2 \\
\hline & Cats & 0 & 1 \\
\hline \multirow[t]{18}{*}{ Prick test } & Total patients tested & 7 & 25 \\
\hline & \multicolumn{3}{|c|}{ Number of patients tested positive: } \\
\hline & Parietaria & 4 & 7 \\
\hline & dust P-dust F & 5 & 11 \\
\hline & Olive & 2 & 4 \\
\hline & Grasses & 1 & 6 \\
\hline & Hazelnut & 1 & 1 \\
\hline & Cereals & 1 & 3 \\
\hline & Cupressaceae & 0 & 1 \\
\hline & Almonds & 0 & 1 \\
\hline & Rice & 0 & 1 \\
\hline & Soja & 0 & 1 \\
\hline & Peas & 0 & 1 \\
\hline & Fagaceae & 0 & 1 \\
\hline & Salicaceae & 0 & 1 \\
\hline & Oleaceae & 0 & 1 \\
\hline & Alternaria & 0 & 1 \\
\hline & Negative & 0 & 3 \\
\hline \multirow[t]{2}{*}{ Specific IgE } & Total patients tested & 7 & 26 \\
\hline & Number of patients & & \\
\hline
\end{tabular}




\begin{tabular}{llll}
\hline & Parietaria & 0 & 2 \\
\cline { 2 - 4 } & Dust mites & 2 & 8 \\
\cline { 2 - 4 } & Olive & 1 & 1 \\
\cline { 2 - 4 } & Grasses & 0 & 2 \\
\cline { 2 - 4 } & Cats & 0 & 2 \\
\cline { 2 - 4 } & Cereals & 1 & 1 \\
\cline { 2 - 4 } & Cupressaceae & 0 & 2 \\
\cline { 2 - 4 } & Pollen & 0 & 1 \\
\cline { 2 - 4 } & Derm. Pteronyssinus-Derm. Farinae & 1 & 2 \\
\cline { 2 - 4 } & Milk & 0 & 1 \\
\cline { 2 - 4 } & Negative & 6 & $\mathbf{3 4}$ \\
\hline Total patients tested & Total IgE $>120$ & 7 & 26 \\
\hline
\end{tabular}

Among the 73 patients in the control group, 28 (38 percent) had nocturnal symptoms, 29 (40 percent) worsened their symptoms during effort, 28 ( 38 percent) had at least one respiratory exacerbation per year, 11 (15 percent) had at least one case of pneumonia per year, and eight (11 percent) were hospitalized at least once per year for asthma exacerbation. On the other hand, of the 28 patients exposed to passive smoking, seven ( 25 percent) of the children had nocturnal symptoms, 12 (43 percent) had respiratory symptoms during effort, six ( 21 percent) presented with at least one case of pneumonia per year, and three (11 percent) were admitted to the hospital at least once per year for asthma exacerbation. Statistical analysis was done using SPSS Pearson chi2 test (Pearson chi2 $=107.0788, \mathrm{P}=$ 0.000). Paternal smoking was positively correlated with a higher number of hospitalizations for asthma (Pearson chi2 $=107.0788, \mathrm{P}=0.000$ ) (Table 2), a higher incidence of lower respiratory tract infections (Pearson chi2 $=$ 207.2906, $\mathrm{P}=0.000$ ) (Table 3), and asthma exacerbations (Pearson chi2 $=103.2490, \mathrm{P}=0.000$ ) (Table 4). Similarly, maternal smoking was positively correlated with a higher number of hospitalizations for asthma (Pearson chi2 $=107.4889, \mathrm{P}=0.000)$ (Table 5), a higher number of lower respiratory tract infections (Pearson chi2 $=102.2478, \mathrm{P}=0.000$ ) (Table 6 ), and asthma exacerbations (Pearson chi2 $=103.1149, \mathrm{P}=0.000)$ (Table 7).

Table 2. Correlation between paternal smoking and the number of hospital admissions for asthma exacerbations per year in exposed asthmatic childr

\begin{tabular}{|c|c|c|c|c|c|c|}
\hline \multirow{2}{*}{$\begin{array}{l}\text { Paternal } \\
\text { Smoking }\end{array}$} & \multicolumn{6}{|c|}{ Hospitalization } \\
\hline & 0 & 1 & 2 & Hospitalization & many & Total \\
\hline \multirow{2}{*}{$\mathbf{0}$} & 75 & 7 & 1 & 0 & 0 & 83 \\
\hline & 83.33 & 77.78 & 100.00 & 0.00 & 0.00 & 81.37 \\
\hline \multirow{2}{*}{1} & 15 & 2 & 0 & 0 & 1 & 18 \\
\hline & 16.67 & 22.22 & 0.00 & 0.00 & 100.00 & 17.65 \\
\hline \multirow{2}{*}{ Fs } & 0 & 0 & 0 & 1 & 0 & 1 \\
\hline & 0.00 & 0.00 & 0.00 & 100.00 & 0.00 & 0.98 \\
\hline \multirow{2}{*}{ Total } & 90 & 9 & 1 & 1 & 1 & 102 \\
\hline & 100.00 & 100.00 & 100.00 & 100.00 & 100.00 & 100.00 . \\
\hline \multicolumn{3}{|c|}{ Pearson chi $2(8)=107.0788$} & \multicolumn{2}{|c|}{$P=0.000$} & & \\
\hline
\end{tabular}


Table 3. Correlation between paternal smoking and the rate of lower respiratory infections per year in asthmatic exposed children

\begin{tabular}{llllll}
\hline Paternal & Infection & & & & Total \\
\cline { 2 - 6 } Smoking & 0 & 1 & 17 & 0 & 83 \\
\hline $\mathbf{0}$ & 70 & 13 & 0 & 0.00 & 80.58 \\
\hline $\mathbf{1}$ & 80.46 & 92.86 & 0.00 & 0 & 18 \\
& 17 & 1 & 0.00 & 0.00 & 17.48 \\
\hline $\mathbf{1 8}$ & 19.54 & 7.14 & 1 & 0 & 1 \\
& 0 & 0 & 100.00 & 0.00 & 1 \\
\hline Fs & 0.00 & 0.00 & 0 & 1 & 0.97 \\
& 0 & 0 & 0.00 & 100.00 & 102 \\
\hline Total & 0.00 & 0.00 & 1 & 1 & 100.00 \\
\hline Pearson chi2 $(\mathbf{9 )}=\mathbf{2 0 7 . 2 9 0 6}$ & 100.00 & 100.00 & & 1 \\
\hline
\end{tabular}

Table 4. Correlation between smoking fathers and the number of exacerbations per year in exposed asthmatic children

\begin{tabular}{|c|c|c|c|c|c|c|}
\hline \multirow{2}{*}{$\begin{array}{l}\text { Paternal } \\
\text { Smoking }\end{array}$} & \multicolumn{6}{|c|}{ Exacerbations } \\
\hline & 0 & 1 & 2 & 3 & Exacerbation & Total \\
\hline \multirow[t]{2}{*}{$\mathbf{0}$} & 54 & 26 & 2 & 1 & 0 & 83 \\
\hline & 80.60 & 86.67 & 66.67 & 100.00 & 0.00 & 81.37 \\
\hline \multirow[t]{2}{*}{1} & 13 & 4 & 1 & 0 & 0 & 18 \\
\hline & 19.40 & 13.33 & 33.33 & 0.00 & 0.00 & 17.65 \\
\hline \multirow[t]{2}{*}{ Fs } & 0 & 0 & 0 & 0 & 1 & 1 \\
\hline & 0.00 & 0.00 & 0.00 & 0.00 & 100.00 & 0.98 \\
\hline \multirow[t]{2}{*}{ Total } & 67 & 30 & 3 & 1 & 1 & 102 \\
\hline & 100.00 & 100.00 & 100.00 & 100.00 & 100.00 & 100.00 \\
\hline \multicolumn{3}{|c|}{ Pearson chi2 $(8)=103.2490$} & \multicolumn{2}{|c|}{$P=0.000$} & & \\
\hline
\end{tabular}

Table 5. Correlation between maternal smoking and the number of hospital admissions for asthma exacerbations per year in exposed asthmatic children

\begin{tabular}{|c|c|c|c|c|c|c|}
\hline \multirow{2}{*}{$\begin{array}{l}\text { Maternal } \\
\text { Smoking }\end{array}$} & \multicolumn{6}{|c|}{ Hospitalization } \\
\hline & 0 & 1 & 2 & Hospitalization & Many & Total \\
\hline \multirow{2}{*}{$\mathbf{0}$} & 76 & 7 & 1 & 0 & 0 & 84 \\
\hline & 84.44 & 77.78 & 100.00 & 0.00 & 0.00 & 82.35 \\
\hline \multirow{2}{*}{1} & 14 & 2 & 0 & 0 & 1 & 17 \\
\hline & 15.56 & 22.22 & 0.00 & 0.00 & 100.00 & 16.67 \\
\hline \multirow{2}{*}{ Ms } & 0 & 0 & 0 & 1 & 0 & 1 \\
\hline & 0.00 & 0.00 & 0.00 & 100.00 & 0.00 & 0.98 \\
\hline \multirow{2}{*}{ Total } & 90 & 9 & 1 & 1 & 1 & 102 \\
\hline & 100.00 & 100.00 & 100.00 & 100.00 & 100.00 & 100.00 . \\
\hline \multicolumn{3}{|c|}{ Pearson chi2 $(8)=107.4889$} & \multicolumn{2}{|c|}{$P=0.000$} & & \\
\hline
\end{tabular}


Table 6. Correlation between maternal smoking and the rate of lower respiratory infections per year in asthmatic exposed children

\begin{tabular}{lllll}
\hline Maternal & Infection & & & Total \\
\cline { 2 - 5 } Smoking & 0 & 1 & Infection & 84 \\
\hline $\mathbf{0}$ & 73 & 11 & 0 & 82.35 \\
\hline $\mathbf{1}$ & 83.91 & 78.57 & 0.00 & 17 \\
& 14 & 3 & 0 & 16.67 \\
\hline $\mathbf{1 8}$ & 16.09 & 21.43 & 0.00 & 1 \\
& 0 & 0 & 1 & 0.98 \\
\hline Total & 0.00 & 0.00 & 100.00 & 1 \\
& 0 & 0 & 1 & 0.97 \\
\hline Pearson chi2 $\mathbf{( 4 )}=\mathbf{1 0 2 . 2 4 7 8}$ & 0.00 & & 100.00 & \\
\hline
\end{tabular}

Table 7. Correlation between maternal smoking and the number of exacerbations per year in exposed asthmatic children

\begin{tabular}{|c|c|c|c|c|c|c|}
\hline \multirow{2}{*}{$\begin{array}{l}\text { Mother } \\
\text { smoker }\end{array}$} & \multicolumn{6}{|c|}{ Exacerbations } \\
\hline & 0 & 1 & 2 & 3 & Exacerbation & Total \\
\hline \multirow{2}{*}{$\mathbf{0}$} & 55 & 26 & 2 & 1 & 0 & 84 \\
\hline & 82.09 & 86.67 & 66.67 & 100.00 & 0.00 & 82.35 \\
\hline \multirow{2}{*}{1} & 12 & 4 & 1 & 0 & 0 & 17 \\
\hline & 17.91 & 13.33 & 33.33 & 0.00 & 0.00 & 16.67 \\
\hline \multirow{2}{*}{ Fs } & 0 & 0 & 0 & 0 & 1 & 1 \\
\hline & 0.00 & 0.00 & 0.00 & 0.00 & 100.00 & 0.98 \\
\hline \multirow{2}{*}{ Total } & 67 & 30 & 3 & 1 & 1 & 102 \\
\hline & 100.00 & 100.00 & 100.00 & 100.00 & 100.00 & 100.00 \\
\hline \multicolumn{3}{|c|}{ Pearson chi2 $(8)=103.1149$} & \multicolumn{2}{|c|}{$P=0.000$} & & \\
\hline
\end{tabular}

Another statistical study made by multiple correspondence analysis showed that having at least one parental smoker was positively correlated with nocturnal symptoms, worsening of symptoms in the effort, the presence of an exacerbation annually, a respiratory infection annually, and an annual hospital admission for asthma exacerbation in the exposed child.

This statistical study also showed that the absence of parental smoking was negatively correlated with nocturnal symptoms, worsening of symptoms in the effort, the presence of an exacerbation annually, a respiratory infection annually, and an annual hospital admission for these exacerbations in the non-exposed child (Figure 1). 


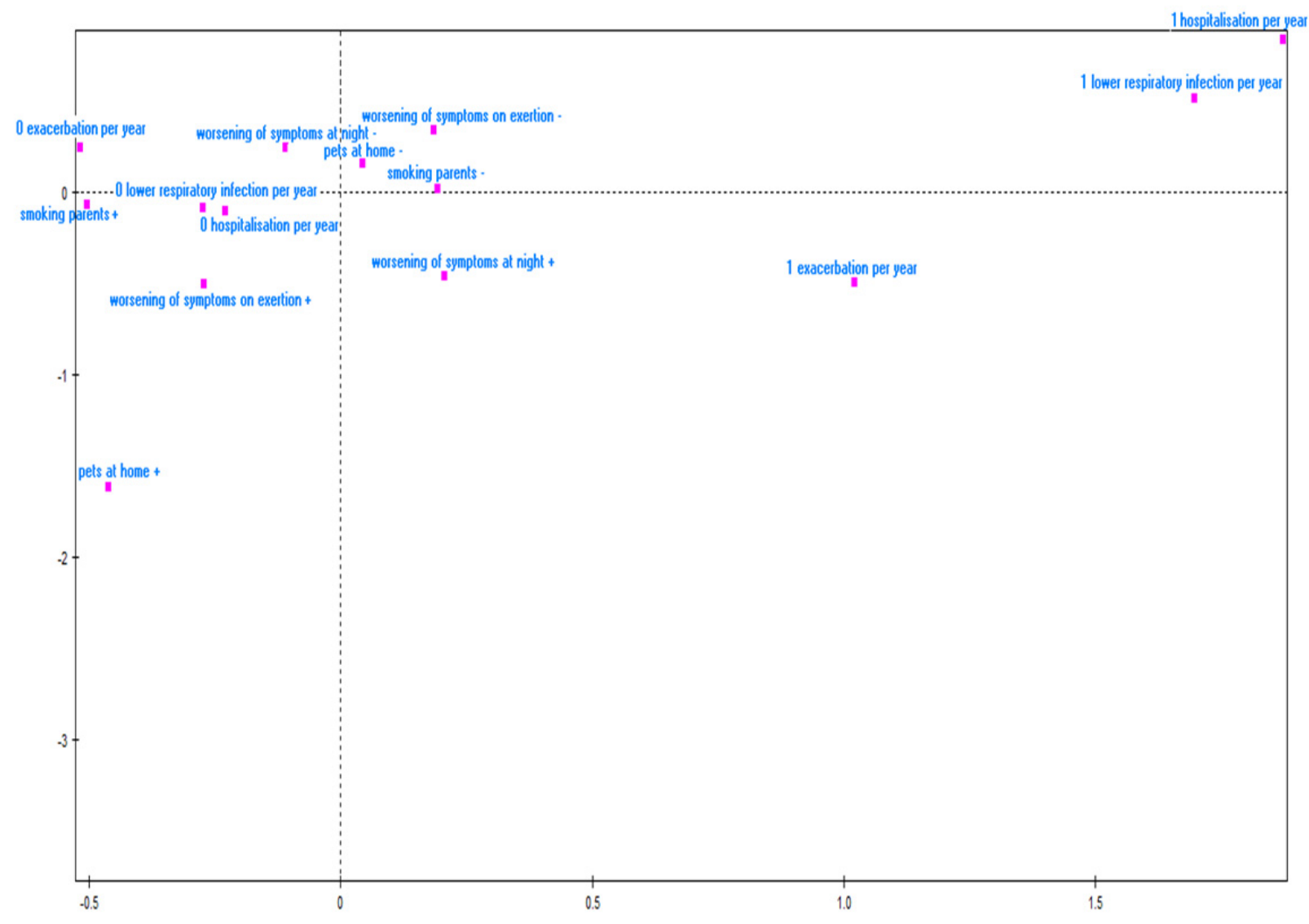

Figure 1. Multiple correspondence analysis

\section{Discussion}

These results are consistent with what has been already demonstrated concerning the harmful effect of passive smoking on respiratory health in general and on asthma in particular. Despite the small number of asthmatic children with parental smokers, our study showed that smoking in any or both parents is correlated with more severe childhood asthma, regardless of the age of the child. Asthmatic children exposed to passive smoking by one of their parents are more likely to need hospitalization at least once per year for their asthma, and suffer more frequently from pneumonia and asthma exacerbations, independently of concomitant allergy.

\section{Conclusion}

Maternal and paternal smoking predisposes an asthmatic child to hospitalization for asthma, more frequent lower respiratory tract infections, and is associated with an increased number of exacerbations per year. Smoking cessation in parents with asthmatic children should be discussed extensively with those parents, showing them objective data about the deleterious effect of tobacco on the health of their children.

\section{Competing Interests Statement}

The authors declare that there are no competing or potential conflicts of interest.

\section{References}

(US), O. on S. and H., (2006). The Health Consequences of Involuntary Exposure to Tobacco Smoke, Centers for Disease Control and Prevention (US). Reteived September 17, 2016, from http://www.ncbi.nlm.nih.gov/pubmed/20669524

Burke, H., Leonardibee, J., Hashim, A., Pineabata, H., Chen, Y., \& Cook, D. G., et al. (2012). Prenatal and passive smoke exposure and incidence of asthma and wheeze: systematic review and meta-analysis. Pediatrics, 129(4), 735 -744. https://doi.org/10.1542/peds.2011-2196 
California Environmental Protection Agency \& Agency, C.E.P. (1997). Health effects of exposure to environmental tobacco smoke. California Environmental Protection Agency. Tobacco Control, 6(4), $346-353$. Retrieved from http://www.druglibrary.org/schaffer/tobacco/caets/ets-main.htm

Smoking, O. O., \& Health (US). (2006). The health consequences of involuntary exposure to tobacco smoke: a report of the surgeon general. Centers for Disease Control \& Prevention.

Comhair, S. A. A., Gaston, B. M., Ricci, K. S., Hammel, J., Dweik, R. A., \& Teague, W. G., et al. (2011). Detrimental effects of environmental tobacco smoke in relation to asthma severity. Plos One, 6(5), e18574. https://doi.org/10.1371/journal.pone.0018574

Gilmour, M. I., Jaakola, M. S., London, S. J., Nel, A., \& Rogers, C. A. (2006). How exposure to environmental tobacco smoke, outdoor air pollutants, and increased pollen burdens influences the incidence of asthma. Environmental health perspectives, 114(4), 627-33. https://doi.org/10.1289/ehp.8380

Nhlb. (2007). Expert panel report 3 (epr-3): guidelines for the diagnosis and management of asthma-summary report 2007. Journal of Allergy \& Clinical Immunology, $120(5$ Suppl), 94-138. https://doi.org/10.1016/j.jaci.2007.09.043

O'Connor, G. T., Weiss, S. T., Tager, I. B., \& Speizer, F. E. (1987). The effect of passive smoking on pulmonary function and nonspecific bronchial responsiveness in a population-based sample of children and young adults. American Review of Respiratory Disease, 135(4), 800. https://doi.org/10.1164/arrd.1987.135.4.800

Ojukwu, E. \& Robinson, M. (2017). Is Secondhand Smoke Exposure Associated With Increased Exacerbation Severity Among Children Hospitalized for Asthma ?

Radic, S. D., Gvozdenovic, B. S., Pesic, I. M., Zivkovic, Z. M., \& Skodric-Trifunovic, V. (2011). Exposure to tobacco smoke among asthmatic children: parents' smoking habits and level of education. International Journal of Tuberculosis \& Lung Disease the Official Journal of the International Union Against Tuberculosis \& Lung Disease, 15(2), 276-280.

Samet, J. M., Tager, I. B. \& Speizer, F. E. (1983). The relationship between respiratory illness in childhood and chronic air-flow obstruction in adulthood. Am Rev Respir Dis, 127(4), 508-523. https://doi.org/10.1164/arrd.1983.127.4.508

Stapleton, M., Howardthompson, A., George, C., Hoover, R. M., \& Self, T. H. (2011). Smoking and asthma. Journal of the American Board of Family Medicine, 24(24), 313-322. https://doi.org/10.3122/jabfm.2011.03.100180

Wang, Z., May, S. M., Charoenlap, S., Pyle, R., Ott, N. L., \& Mohammed, K., et al. (2015). Effects of secondhand smoke exposure on asthma morbidity and health care utilization in children: a systematic review and meta-analysis. Annals of Allergy Asthma \& Immunology Official Publication of the American College of Allergy Asthma \& Immunology, 115(5), 396. https://doi.org/10.1016/j.anai.2015.08.005

\section{Copyrights}

Copyright for this article is retained by the author(s), with first publication rights granted to the journal.

This is an open-access article distributed under the terms and conditions of the Creative Commons Attribution license (http://creativecommons.org/licenses/by/4.0/). 